\title{
Analysis of nutrient contents and quality feature extraction of clustered seeds using Digital Image Processing
}

\author{
**Ms. Jyoti Atwal*, Mr. Satyajit Sen Purkayastha **, \\ * (M. Tech student Deptt. of Electronics and Comm., I.E.T, Bhaddal)) \\ **(Asstt. Professor, Deptt. of Electronics and Comm, I.E.T, Bhaddal)
}

\begin{abstract}
Digital image analysis method was developed to analyse individual grain kernels nutrients . In this methodology for the analysis of the grain morphology of particular importance is rice and for the quantitative comparison of the quality of their grain ordering based on the distances between nearest neighbors and their angular order. To recognize the growing low quality defining characteristics for identification is desirable as fraudulent mislabeling of rice grain varieties. present work a The digital imaging processing technique has been devised in order to investigate different types of characteristics to identify different rice varieties. In image processing base application performing hard core processing techniques like Raster Scanning for dimensional analysis, HSI (Hue-SaturationIntensity) model for morphological properties analysis. The morphological features were extracted and processed by linear discriminant analysis to improve the efficiency of the identification process. Now here we will work on physical separation and nutrient content of seeds using different methods like Erosion and Dilation, Watershed Model and Line draw method.
\end{abstract}

Keywords - Erosion and Dialation, DIP, Nutrients, Raster scanning, HSI, grain quality, Watershed model.

\section{INTRODUCTION}

Digital image processing remains a challenging domain of programming for several reasons. First the issue of digital image processing appeared relatively late in computer history, it had to wait for the arrival of the first graphical operating systems to become a true matter. Secondly, digital image processing requires the mostcareful optimisations and especially for real time applications. Comparing image processing and audio processing is a good way to fix ideas. In the rice industry there are various qualities in the form of grains as Fig. 1 represents bulk of rice and Fig. 3 bulk of brown rice In commodity crop of particular importance is rice all of these techniques are employed in an inexpensive imaging system that is non-intrusive and

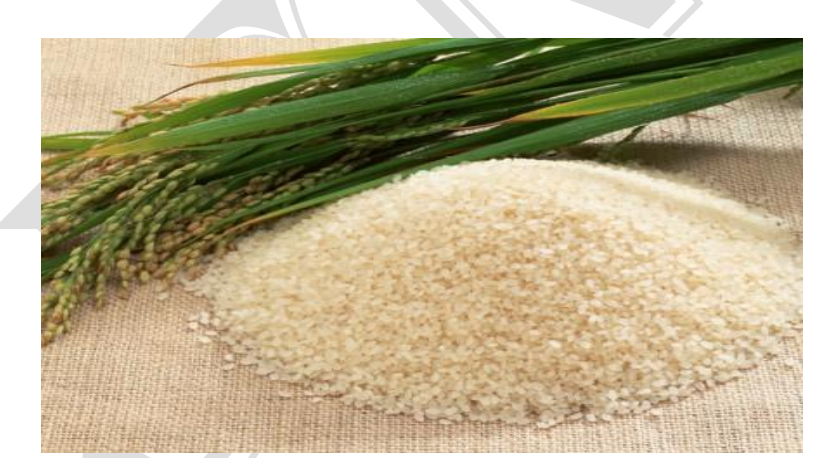

Fig.1: Image represents bulk of rice.

harmless. This process will provide mathematical foundations and practical techniques for digital manipulation of images, image acquisition, preprocessing and segmentation techniques.

\section{LITERATURE REVIEW}

Morphology is a broad set of image processing operations that process images based on shapes .In this we input to this application will be provided by a simple flat bed scanner whose properties will be set to $200 \mathrm{dpi}$ (Dots per Inch) for accuracy point of view in dimensional analysis and low error rate and the image will be saved in bitmap(bmp) format .And to make reference for our processing black background will be provided during scan. No additional hardware requirement is there. Even no software requirement will be there after final compilation. An Exe file will be generated for use after development. After inputting image from scanner image will be opened in the application scenario. Before the processing starts the image will be converted to binary image means in 0,1 format. That processing system acquires image acquisition, image processing, and feature extraction. 


\section{Ms. Jyoti Atwal, Mr. Satyajit Sen Purkayastha/ IOSR Journal of Engineering (IOSRJEN) \\ www.iosrjen.org \\ ISSN : 2250-3021}

Vol. 2 Issue 2, Feb.2012, pp. 288-292
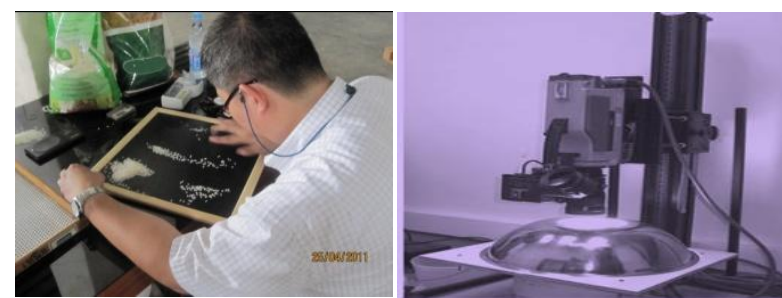

Fig.:2 Physical inspection and identification of rice

While performing morphological operations such as erosion and dilation of binary image to separate touching grain kernels in images. Physical inspection and identification of rice is done as showing in Fig.2.The edge of each grain kernel in an image was segmented. Erosion removes pixels on object boundaries and dilation adds pixels to the boundaries of objects in an image. A new approach to segment diffusion of image in Watershed transform model. In this model four parameters to be adjusted and the number of regions in which the image should be segmented and make it easier . Line draw algorithm determines the points in an n-dimensional raster should be plotted in order to form a close approximation to a straight line between two given points. It is commonly used to draw lines on a computer screen, as it uses only integer addition, subtraction and bit shifting, all of which are very cheap operations in standard computer architectures.

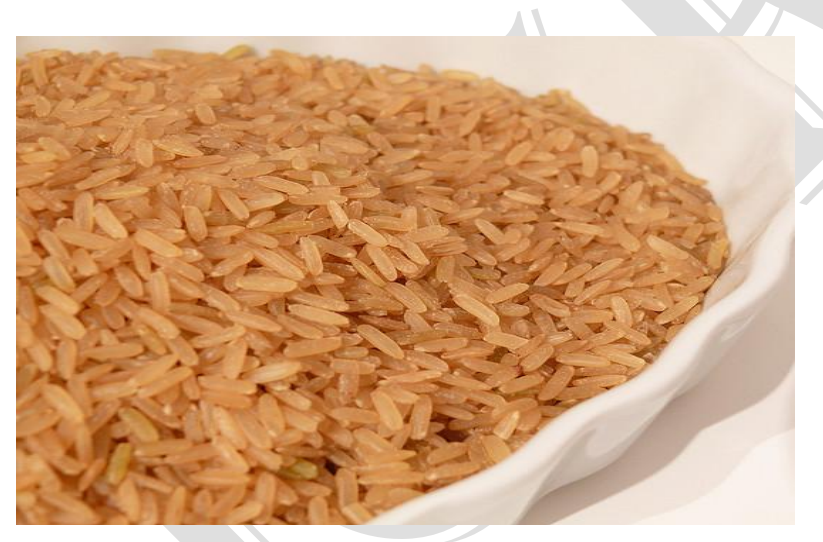

Fig.3: Bulk of brown rice

\section{PROPOSED APPROACHES}

\section{A. EROSION}

Morphology is a broad set of image processing operations that process images based on shapes. Morphological operations apply a structuring element to an input image, creating an output image of the same size. In a morphological operation, the value of each pixel in the output image is based on a comparison of the corresponding pixel in the input image with its neighbors. Fig.4 (a) Represents the original image and 4(b) is the image after erosion.

By choosing the size and shape of the neighborhood, we can construct a morphological operation that is sensitive to specific shapes in the input image.

Erosion is when materials are removed from the surface and changed into something else. It usually occurs due to transport by wind, water, or ice; by down-slope creep of soil and other material under the force of gravity; or by living organisms, such as burrowing animals, in the case of bioerosion. Although erosion is a natural process human land use policies also have had an effect on erosion, especially industrial agriculture, deforestation, and urban sprawl. Land that is used for industrial agriculture generally experiences a significantly greater rate of erosion than that of land under natural vegetation, or land used for sustainable agricultural practices.

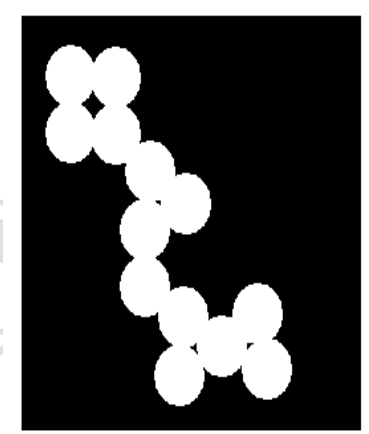

Fig.4: (a) Original Image

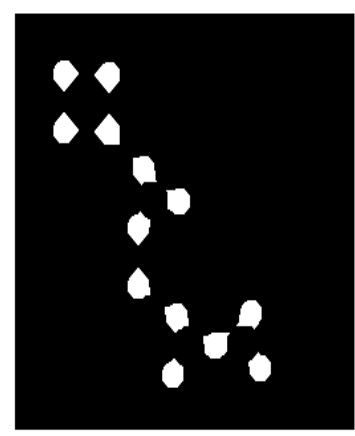

Fig.4: (b) Eroded Image
This is particularly true if tillage is used, which reduces vegetation cover on the surface of the soil and disturbs both soil structure and plant roots that would otherwise hold the soil in place. However, improved land use practices can limit erosion, using techniques such as terrace-building, no-till, and tree planting. Erosion is distinguished from weathering, which is the process of chemical or physical breakdown of the minerals in the rocks. The value of the output pixel is the minimum value of all the pixels in the input pixel's neighborhood. In a binary image, if any of the pixels is set to 0 , the output pixel is set to 0

\section{B. DILATION}




\section{Ms. Jyoti Atwal, Mr. Satyajit Sen Purkayastha/ IOSR Journal of Engineering (IOSRJEN) \\ www.iosrjen.org \\ ISSN : 2250-3021}

Vol. 2 Issue 2, Feb.2012, pp. 288-292

Dilation is one of the basic operations in mathematical morphology. Originally developed for binary images, it has been expanded first to grayscale images, and then to complete lattices. The dilation operation usually uses a structuring element for probing and expanding the shapes contained in the input imagr.To dilate an image, use the imdilate function. The imdilate function accepts are the input image to be processed (grayscale, binary, or packed binary image) and the structuring element object, returned by the strel function, or a binary matrix defining the neighborhood of a structuring element. Dilation generally increases the sizes of objects, filling in holes and broken areas, and connecting areas that are separated by spaces smaller than the size of the structuring element. With grayscale images, dilation increases the brightness of objects by taking the neighborhood maximum when passing the structuring element over the image. With binary images, dilation connects areas that are separated by spaces smaller than the structuring element and adds pixels to the perimeter of each image object as represents in Fig. 5 below.

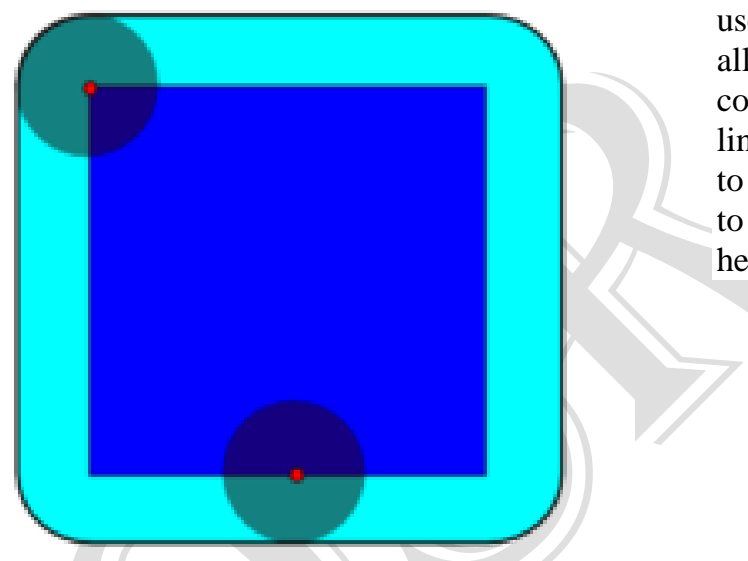

Fig5. Shows the dilation by dark-blue square

with

a disk, resulting in the light-blue square.

\section{WATERSHED MODEL}

The watershed management approach seeks to effectively protect our water resources by taking into account the entire watershed. Successful watershed management requires the participation and involvement of the entire community within the watershed boundaries, including industry, government, business and citizens. The watershed transform is a popular segmentation method coming from the field of mathematical morphology as showing in Fig.6. The intuitive description of this transform is quite simple: if we consider the image as a topographic relief, where the height of each point is directly related to its gray level, and consider rain gradually

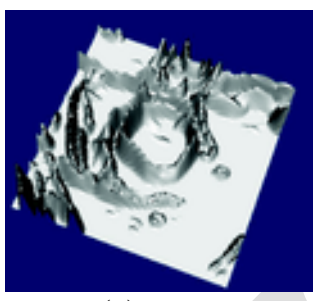

(a)

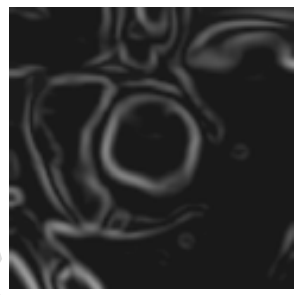

(b)
Fig6. Shows (a) original image (b) watershed relief

gradient image.

\section{LINE DRAW METHOD}

The line draw algorithm is an algorithm which determines which points in an n-dimensional raster should be plotted in order to form a close approximation to a straight line between two given points. It is commonly used to draw lines on a computer screen, as it uses only integer addition, subtraction and bit shifting, all of which are very cheap operations in standard computer architectures. The version above only handles lines that descend to the right. We would of course like to be able to draw all lines. The first case is allowing us to draw a line as in Fig.7 that still slope downwards but head in the opposite direction.

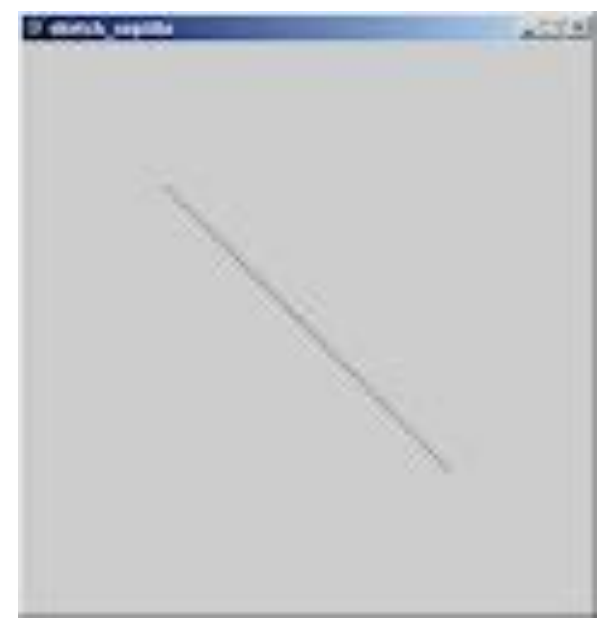

Fig7. Represent straight line image.

\section{CONCLUSION}

The Image processing application has been widely used in our daily life. In this image segmentation is a necessary step for analysis an image has low level processing in digital image processing. In morphological features of grains the dimensional measurement can be done using different techniques of 


\section{Ms. Jyoti Atwal, Mr. Satyajit Sen Purkayastha/ IOSR Journal of Engineering (IOSRJEN) \\ www.iosrjen.org \\ ISSN : 2250-3021}

Vol. 2 Issue 2, Feb.2012, pp. 288-292

image processing. By Raster scanning technique we measure the seed dimension like length, breadth, ratio, weight and area of grain colour image segmentation can be seen as extension of gray image into the colour image. For calculating the textural properties of granular material with image analysis is generally troubled by the fact that touching grain sections merge into single features. For this we are using Erosion and Dilatation, Watershed model and Line draw algorithm, the image processing techniques which can classify the accuracy of grain analyzed. All the grain types could be classified with closed to $100 \%$ classification accuracy by above said applications.

\section{REFERENCES:}

1. Wellington, S.L. and Vinegar, H.J.: "X-Ray Computerized Tomography," Journal of Petroleum Technology, August, 1987, p. 885.

2. Vinegar, H.J.: "X-Ray CT and NMR Imaging of Rocks," Journal of Petroleum Technology, March, 1986, p. 257. SAUDI ARAMCO JOURNAL OF TECHNOLOGY SUMMER 200653

3. Withjack, E.M.: "Computed Tomography for RockProperty Determination and Fluid-Flow Visualization," SPE Formation Evaluation, December, 1988, p. 696.

4. Kantzas, A: "Investigation of Physical Properties of Porous Rocks and Fluid Flow Phenomena in Porous Media Using Computer Assisted Tomography," In Situ, Vol. 14, No. 1, 1990, p. 77.

5. Saner, S.: "A Review of Computer Tomography and Petrophysical Applications (Sabbatical Research, 1993- 1994)," King Fahd University of Petroleum and Minerals, Dhahran, KSA, March 1994, pp. 118.

6. Akin, S. and Kovscek, A.R.: "Use of Computerized Tomography in Petroleum Engineering Research," Annual Report of SUPRI TR 127, Stanford University, Stanford, CA, August 2001, pp. 63-83.

7. Withjack, E. M., Devier, C. and Michael, G.: "The Role of X-Ray Computed Tomography in Core Analysis," SPE 83467 presented at the SPE Western Regional/AAPG Pacific Section Joint Meeting held in Long Beach, CA, May 19-24, 2003.

8. Van Geet, M., Swennen, R. and Wevers, M.: "Quantitative Analysis of Reservoir Rocks by
Microfocus X-Ray Computerised Tomography," Sedimentary Geology, 132 (2000), pp. 25-36.

9. Alvarado, F.E., Grader, A.S., Karacan, O. and Halleck, P.M.: "Visualization of Three Phases in Porous Media using Micro Computed in Pau, France, September 24-28, 2003.

10. Coles, M.E., Hazlett, R.D., Muegge, R.L., Jones, K.W., Andrews, B., Dowd, B., Siddons, P., Peskin, A., Spanne, P. and Soll, W.E.: "Developments in Synchrotron XRay Microtomography with Applications to Flow in Porous Media," SPE 36531, presented at the 1996 Annual Technical Conference and Exhibition held in Denver, CO, October 5-9, 1996.

11. Krinsley, D.H., Pye, K., Boggs, Jr., S. and Tovey, N.K.: Backscattered Scanning Electron Microscopy and Image Analysis of Sediments and Sedimentary Rocks, Cambridge University Press, Cambridge, UK, 1998, p. 1.

12. Brown, R.I.S. and Fatt, I.: "Measurement of Fractional Wettability of Oil Fields' Rocks by Nuclear Magnetic Relaxation Method," SPE 743G, Society of Petroleum Engineers, Richardson, TX, 1956.

13. Kenyon, W. E.: "Petrophysical Principles of Applications of NMR Logging," The Log Analyst, March-April, 1997, p. 21.

14. Vinegar, H.J.: "Introduction to Special Log Analyst Issue on NMR Logging," The Log Analyst, Vol. 37, No. 6, 1996.

15. Bloembergen, N., Purcell, E.M., and Pound, R.V.: "Relaxation Effects in Nuclear Magnetic Absorption," Physics Review, Vol. 73 (1948), p. 679.

16. Yuan, H.H. and Swanson, B.F.: "Resolving PoreSpace Characteristics by Rate-Controlled Porosimetry," SPE Formation Evaluation, Vol. 4, No. 1, March 1989, pp. 17-24.

17. ASPE-730 Product Overview, CoreTest Systems, Inc. Moran Hill, CA (http://www.coretest.com/pdf/aspe-730.pdf).

18. Cantrell, D.I. and Hagerty, R.M.: "Reservoir Rock Classification, Arab-D Reservoir, Ghawar Field, Saudi Arabia," GeoArabia, Vol. 8, No. 3, 2003, pp. 435-462. 


\section{Ms. Jyoti Atwal, Mr. Satyajit Sen Purkayastha/ IOSR Journal of Engineering (IOSRJEN) \\ www.iosrjen.org \\ ISSN : 2250-3021}

Vol. 2 Issue 2, Feb.2012, pp. 288-292

19. Siddiqui, S., Okasha, T.M., Funk, J.J. and Harbi, A.M.: "New Representative Sample Selection Criteria for Special Core Analysis," SCA paper No. 2003-40, Proceedings of the 2003 SCA Symposium held in Pau, France, September 24-28, 2003.

20. Siddiqui, S.: "Method of Depth Matching Using Computerized Tomography," United States Patent No. 6,876,721 B2, granted April 5, 2005.

21. Ehrlich, R., Crabtree, S.J., Horkowitz, K.O. and Horkowitz, J.P.: "Petrography and Reservoir Physics I: Objective Classification of Reservoir Porosity," AAPG Bulletin (Oct. 1991), Volume 75, No. 10, p. 1547.

22. Allen, D., Flaum, C., Ramakrishnan, T.S., Bedford, J., Castelijns, K., Fairhurst, D., Gubelin, G., Heatorn, N., Minh, C.C., Norville, M.A., Seim, M.R., Pritchard, T. and Ramamoorthy, R.: "Trends in NMR Logging," Oilfield Review, Autumn 2000, pp. 2-18.

23. Montgomery D. C., 2000. Design and Analysis of Experiments. Wiley. Chichester Majumdar, S., D.S. Jayas, 2000a. Classification of cereal grains using machine vision. Morphology models. Transactions of the ASAE 43(6):1669-1675.

24. Majumdar, S., D.S. Jayas, 2000b. Classification of cereal grains using machine vision. II. Colour models. Transactions of the ASAE 43(6):16771680.

25. Majumdar, S., D.S. Jayas, 2000c. Classification of cereal grains using machine vision. Texture models. Transactions of the ASAE 43(6):16811687.

26. Majumdar, S., D.S. Jayas, 2000d. Classification of cereal grains using machine vision. Combined morphology, colour, and texture models. Transactions of the ASAE 43(6):1689-1694.

27. Paliwal, J., N. S. Shashidhar, D. S. Jayas, 1999. Grain kernel identification using kernel signature. Transactions of the ASAE 42(6): 1921-1924.

28. Putnam, D. F., R. G. Putnam, 1970. Canada: A Regional Analysis. Dent and Sons, Inc. Toronto . Shashidhar, N. S.; D. S. Jayas, T. G. Crowe, N. R. Bulley, 1997. Processing of digital images of touching kernels by ellipse fitting. Canadian AgriculturalEngineering 39:139-142.

29. Leroy, L.W.: Subsurface Geologic Methods, Second Printing, Second Edition, Colorado School of Mines, Department of Publications, Golden, CO, 1951, p. 118.

30. Egermann, P., Lenormand, R. and Longeron, D.: "A Fast and Direct Method of ermeability Measurements on Drilled Cuttings," SPE 77563 presented at the 2002 Annual Technical Conference and Exhibition held in San Antonio, TX, September 29 - October 2, 2002. 